\title{
Randomised trial of once-daily vilanterol in children with asthma on inhaled corticosteroid therapy
}

\author{
Amanda J. Oliver ${ }^{1 *}$, Ronina A. Covar², Caroline H. Goldfrad ${ }^{1}$, Ryan M. Klein ${ }^{3}$, Søren E. Pedersen ${ }^{4}$, \\ Christine A. Sorkness ${ }^{5}$, Susan A. Tomkins ${ }^{1}$, César Villarán ${ }^{6}$ and Jonathan Grigg ${ }^{7}$
}

\begin{abstract}
Background: Inhaled corticosteroids (ICS) are effective maintenance treatments for childhood asthma; however, many children remain uncontrolled. Vilanterol $(\mathrm{VI})$ is an inhaled long-acting beta-2 agonist which, in combination with the ICS fluticasone furoate, is being explored as a once-daily treatment for asthma in children. We evaluated the dose-response, efficacy, and safety of once-daily VI $(6.25 \mu \mathrm{g}, 12.5 \mu \mathrm{g}$ and $25 \mu \mathrm{g})$ administered in the evening over 4 weeks, on background fluticasone propionate (FP) in children with asthma inadequately controlled on ICS.

Methods: This was a Phase Illb, multicentre, randomised, double-blind, parallel-group, placebo-controlled study in children ages 5-11 years with persistent asthma on ICS and as-needed short-acting beta-agonist. The study comprised a 4-week run-in, 4-week treatment period, and 1-week follow-up. From study start, children replaced their current ICS with open-label FP $100 \mu \mathrm{g}$ twice daily. Children were randomised to receive placebo, VI $6.25 \mu \mathrm{g}$, VI $12.5 \mu \mathrm{g}$ or VI $25 \mu \mathrm{g}$ once daily. Primary endpoint was treatment difference between VI 25 and placebo groups in mean change from baseline in evening peak expiratory flow averaged over the 4-week treatment. Secondary endpoints included change from baseline in trough forced expiratory volume in one second $\left(\mathrm{FEV}_{1}\right)$ at Week 4 and change from baseline in percentage of rescue-free and symptom-free 24-h periods. Safety assessments included incidence of adverse events (AEs) and asthma exacerbations.
\end{abstract}

Results: In total, 456 children comprised the intention-to-treat population. The adjusted treatment difference between $\mathrm{VI} 25$ and placebo groups for the primary endpoint was not statistically significant $(p=0.227)$ so no statistical inference was made for other $\mathrm{VI}$ dose comparisons or other endpoints. No difference in change from baseline in trough $\mathrm{FEV}_{1}$ was observed for any VI treatments versus placebo; however, VI 25 resulted in an additional 0.6 rescue-free days and 0.7 symptom-free days per week versus placebo. The incidence of AEs was slightly higher in the $\mathrm{VI}$ groups (28-33 \%) versus placebo (22\%). Nine children experienced asthma exacerbations during the treatment period.

Conclusion: VI plus FP did not result in significant improvements in lung function versus placebo plus FP, but was well tolerated at all doses assessed.

Trial registration: NCT01573767 (ClinicalTrials.gov).

Keywords: Asthma, Children, Dose response, Efficacy, Fluticasone propionate, Safety, Vilanterol

\footnotetext{
*Correspondence: amanda.j.oliver@gsk.com

'GlaxoSmithKline, Stockley Park West, 1 - 3 Iron Bridge Road, Uxbridge,

Middlesex UB11 1BT, UK

Full list of author information is available at the end of the article
} 


\section{Background}

Asthma is common in children and is a leading cause of childhood hospitalisation [1]. National and international guidelines advocate the use of inhaled long-acting beta- 2 agonists (LABA) in combination with inhaled corticosteroids (ICS) as maintenance therapy for children ages 5-11 years who remain symptomatic despite medium doses of ICS [2, 3]. A network meta-analysis including over 12,000 patients across 35 studies found that combined ICS/LABA treatments were more effective than low-dose ICS in preventing asthma exacerbations among paediatric patients [4]. In addition, studies indicate that the addition of LABA to a low dose of ICS can provide benefits such as improved asthma control in some children compared with increasing the ICS dose [5] and a reduced impact on growth by $1.2 \mathrm{~cm} /$ year compared with double the dose of ICS [6].

Despite the availability of effective therapies, many children with asthma remain uncontrolled, with low adherence proposed as a potential contributing factor [7, 8]. In addition, studies in adult and adolescent patients using dry powder inhalers for treatment of asthma and chronic obstructive pulmonary disease have shown that adherence with a once-daily regimen is greater than with a twicedaily regimen $[9,10]$. However, currently available ICS/ LABA combination therapies require a twice-daily regimen $[11,12]$.

Vilanterol (VI) is a potent, inhaled LABA which, in combination with the ICS fluticasone furoate (FF), has been approved for the treatment of asthma in adults and adolescents in the EU, and in adults in the US [13-15]. In preclinical in vitro studies, VI demonstrated a selectivity profile for beta- 2 adrenoceptors (over beta- 1 and beta-3 adrenoceptors) that was similar to salmeterol and greater than formoterol and indacaterol [16]. Persistence and reassertion studies also showed a persistence of action comparable with indacaterol and greater than formoterol [16]. VI is currently being explored as the LABA component of FF/VI for once-daily treatment for asthma in children [17]. The objective of this study was to evaluate the dose-response, efficacy, and safety of three doses of VI $(6.25 \mu \mathrm{g}, 12.5 \mu \mathrm{g}$ and $25 \mu \mathrm{g})$ administered once daily in the evening over a 4-week treatment period whilst on background fluticasone propionate (FP) therapy to children with asthma who were inadequately controlled on ICS.

\section{Methods}

\section{Study design}

This was a Phase IIb, multicentre, randomised, doubleblind, parallel-group, placebo-controlled (with rescue medication) study in children ages 5-11 years with persistent asthma who were still symptomatic on low-dose ICS (ClinicalTrials.gov identifier NCT01573767). The study design consisted of a 4-week run-in period, a 4-week treatment period and a 1-week follow-up (contact) period. At the start of the run-in period, children replaced their current asthma medication with open-label FP $100 \mu \mathrm{g}$ twice daily via DISKUS ${ }^{\bullet}$ ACCUHALER $^{\odot}$ (GlaxoSmithKline), which they continued to take for the duration of the study. A total of 73 centres in 14 countries (Argentina, Chile, Georgia, Germany, Japan, Mexico, Peru, Philippines, Poland, Puerto Rico, Slovakia, South Africa, United States of America and Ukraine) randomised subjects.

\section{Participants}

Children eligible for inclusion were males and premenarchial females with inadequately controlled asthma, ages 5-11 years, with at least a 6-month history of asthma and who had been receiving a stable dose of a ICS (total daily dose of FP 200-250 $\mu$ g or equivalent) and rescue short-acting inhaled beta-agonist (SABA) for at least 4 weeks prior to screening. Eligible children had a prebronchodilator peak expiratory flow (PEF) of 50-90\% of their best post-bronchodilator value. Excluded children had: a history of life-threatening asthma; a change in asthma medication within 4 weeks of screening; an asthma exacerbation (defined as either requiring the use of systemic corticosteroids for $\geq 3$ days, a depot corticosteroid injection within 3 months prior to screening, or hospitalisation for asthma within 6 months prior to screening); or a concurrent respiratory disease or any other clinically significant medical condition.

At the end of the run-in period, children eligible for randomisation had a pre-bronchodilator PEF of 50-90\% of their best post-bronchodilator value, had demonstrated symptoms of asthma and/or daily use of albuterol/salbutamol on $\geq 3$ of the last 7 consecutive days of the run-in period, complied with the run-in medication on $\geq 4$ of the last 7 consecutive days of the run-in period and had completed all questions on the Daily Diary on $\geq 4$ out of the 7 days during the screening period. Children could not have experienced an asthma exacerbation between screening and randomisation.

The study was conducted in accordance with the ethical principles outlined in the Declaration of Helsinki and was approved by the relevant ethics committee or institutional review board at each investigational centre. Written informed consent was obtained from two parents/ legal guardians. If applicable, the child had to be able and willing to give assent to take part in the study according to the local requirements. The investigator was accountable for determining a child's capacity to assent.

\section{Treatment and assessments}

Children were randomly assigned (1:1:1:1) to receive either placebo, VI $6.25 \mu \mathrm{g}$, VI $12.5 \mu \mathrm{g}$, or VI $25 \mu \mathrm{g}$ once 
daily as their double-blind evening treatment (between $3 \mathrm{pm}$ and $9 \mathrm{pm}$ ) in addition to continuing open-label FP $100 \mu \mathrm{g}$ twice daily. Randomisation was performed via an interactive voice response system whereby children were assigned a randomisation number from a randomisation schedule created by GSK. Children were issued with a daily eDiary and a peak flow meter, and recorded morning and evening PEF, daytime and night time asthma symptom scores, day and night inhalations of SABA and the use of open-label ICS medication during the run-in period. Pre-dose forced expiratory volume in one second $\left(\mathrm{FEV}_{1}\right)$ was measured electronically by spirometer at evening study visits at screening, randomisation, Week 2 and Week 4 . These measurements were taken within $\pm 1 \mathrm{~h}$ of the time $\mathrm{FEV}_{1}$ was measured at baseline and approximately $24 \mathrm{~h}$ after the child's last evening dose. Children who were unable to perform acceptable quality $\mathrm{FEV}_{1}$ at randomisation did not have to perform the spirometry assessments at subsequent study visits, however, data from these children were still collected for all other endpoints.

The primary endpoint was the mean change from baseline in daily pre-dose trough evening PEF, recorded using an eDiary, averaged over the 4-week treatment period. Secondary endpoints were: 1) change from baseline in evening study visit trough $\mathrm{FEV}_{1}$ at the end of the 4-week treatment period (using last observation carried forward [LOCF] for imputation of missing post-baseline $\mathrm{FEV}_{1}$ values); 2) change from baseline in percentage of rescuefree and symptom-free 24-h periods averaged over the 4-week treatment period; 3) change from baseline in morning PEF averaged over the 4-week treatment period; and 4) mean change from baseline in morning and evening PEF over the last 7 days of the treatment period. Other endpoints were change from baseline in childhood asthma control test (cACT) score at the end of the 4-week treatment period and the percentage of subjects controlled, defined as a cACT score $\geq 20$. A post-hoc analysis was carried out to determine the change from baseline in cACT score according to whether children had a baseline cACT score of $<20$ or $\geq 20$.

Pharmacokinetic (PK) blood samples were collected pre-dose and 10-15 min post-dose during the Week 4 visit. Plasma samples were analysed for VI using techniques based on solid phase extraction followed by highperformance liquid chromatography and tandem mass spectrometry analysis (the lower limit of quantification [LLQ] was $10 \mathrm{pg} / \mathrm{mL}$, using a $200 \mu \mathrm{L}$ aliquot).

Safety was assessed by incidence of adverse events (AEs) and exacerbations throughout the 4-week treatment period; vital signs (pulse rate, systolic and diastolic blood pressure $[\mathrm{BP}]$ ) at randomisation and at Week 2, Week 4 or early withdrawal; pre-dose and post-dose electrocardiogram (ECG) at randomisation and at Week 4 or early withdrawal; and laboratory assessments (haematology, clinical chemistry and liver function tests) at screening, Week 4 or early withdrawal.

\section{Statistical analysis}

With 460 children (115 per treatment group) the study had $90 \%$ power assuming a difference of $12 \mathrm{~L} / \mathrm{min}$ between VI and placebo in evening PEF, a standard deviation of $28 \mathrm{~L} / \mathrm{min}$ and significance declared at the two-sided $5 \%$ level. In order to account for multiplicity across treatment comparisons for the primary efficacy endpoint, a step-down closed testing procedure was applied whereby inference for VI $12.5 \mu \mathrm{g}$ versus placebo was dependent upon statistical significance having first been achieved for VI $25 \mu \mathrm{g}$ versus placebo. Similarly, inference for VI $6.25 \mu \mathrm{g}$ versus placebo was dependent upon statistical significance having first been achieved for VI $12.5 \mu \mathrm{g}$ versus placebo.

The intention-to-treat (ITT) population comprised all children randomised to treatment who received $\geq 1$ study medication; the per-protocol (PP) population comprised all children in the ITT population who did not have any full protocol deviations; and the PK population consisted of children in the ITT population for whom a PK sample was obtained and analysed for VI.

The analysis of the primary efficacy endpoint was performed using an analysis of covariance (ANCOVA) model allowing for the effects due to baseline evening PEF, region, sex, age and treatment group on the ITT and PP populations. Missing data were not imputed in this analysis. Five sensitivity analyses were performed to examine the impact of missing data on the primary endpoint: one mixed modelling repeated measures (MMRM) model analysis, and four multiple imputation sensitivity analyses. The MMRM analysis allowed for effects due to baseline evening PEF, region, sex, age, week and treatment group, including week-by-treatment and week-by-baseline interaction terms. The four imputation sensitivity analyses analysed the mean change from baseline in evening PEF using a Missing at Random approach, a Copy Increment from Reference approach, a Jump to Reference approach and a Copy Reference approach. An average treatment effect across Weeks 1-4 was obtained for all sensitivity analyses of the primary endpoint. Three further supporting analyses were also performed on the primary endpoint; these were dose response models, Bayesian analyses with non-informative priors and a MMRM model presenting estimates from each week.

Statistical analyses for secondary endpoints were performed using ANCOVA models with effects due to baseline, region, sex, age and treatment group. For trough $\mathrm{FEV}_{1}$ and morning/evening PEF at the endpoint, missing data was imputed using LOCF. Programming was performed using SAS Version 9.1.3 or later. 
Percent predicted $\mathrm{FEV}_{1}$ values at screening and baseline were not pre-specified and are reported as posthoc analyses.

\section{Results}

\section{Demographics}

A total of 1208 children were screened; 463 children were randomised with 456 (98\%) children included in the ITT population (Fig. 1). Overall, 81 (18\%) children withdrew prematurely from this 4-week study, the majority (62 children, $14 \%$ ) withdrawing due to lack of efficacy. The study period, from the first screening to the last visit, was from April 2012 to April 2014. Demographics were comparable between the four treatment groups and are summarised in Table 1. Lung function measures at screening and baseline are shown in Table 2. PEF and FEV 1 values were similar across treatment groups and stable during the run-in period with open-label FP.

\section{Primary endpoint}

The adjusted treatment differences in the mean change from baseline in daily pre-dose trough evening PEF versus placebo were $5.5 \mathrm{~L} / \mathrm{min}, 6.4 \mathrm{~L} / \mathrm{min}$ and $4.4 \mathrm{~L} / \mathrm{min}$, for the VI 6.25, VI 12.5 and VI 25 groups, respectively (Fig. 2 and Table 3). The adjusted treatment difference between the VI 25 and placebo groups was not statistically significant $(p=0.227)$. Therefore, in accordance with the step-down closed testing procedure, no statistical inference was made for the comparisons of VI $12.5 \mu \mathrm{g}$ or VI $6.25 \mu \mathrm{g}$ with placebo. The analysis of the primary endpoint using the PP population plus all sensitivity and supporting analyses using the ITT population supported the findings of the primary analysis. There was no apparent VI doseordering in the evening PEF treatment difference values from placebo.

\section{Secondary endpoints}

Since the primary endpoint did not reach statistical significance, no inference was made for the secondary endpoints. A total of $384(84 \%)$ children completed a technically acceptable pre-bronchodilator $\mathrm{FEV}_{1}$ assessment at baseline. Of these, a total of $323(71 \%)$ children and 291 (64. \%) children also completed an acceptable $\mathrm{FEV}_{1}$ assessment at Week 2 and Week 4, respectively. The analysis of change from baseline in trough $\mathrm{FEV}_{1}$ at Week 4 (LOCF) included 340 (75\%) children in the ITT population who provided technically acceptable $\mathrm{FEV}_{1}$ data both at baseline and at post-baseline. There was little difference in the change from baseline in trough $\mathrm{FEV}_{1}$ at Week 4 for each of the VI treatments compared with placebo (Table 3).

Over the treatment period, the greatest treatment difference in change from baseline in the percentage of rescue-free 24-h periods was observed in the VI 25 treatment group when compared with placebo (Table 3 ). This equated to an additional 0.6 rescue-free $24-\mathrm{h}$ periods per week for children. For symptom-free days, the treatment differences observed between placebo and the VI 12.5 and VI 25 treatment groups, respectively, equate to an additional 0.6 and 0.7 symptom-free days per week. No

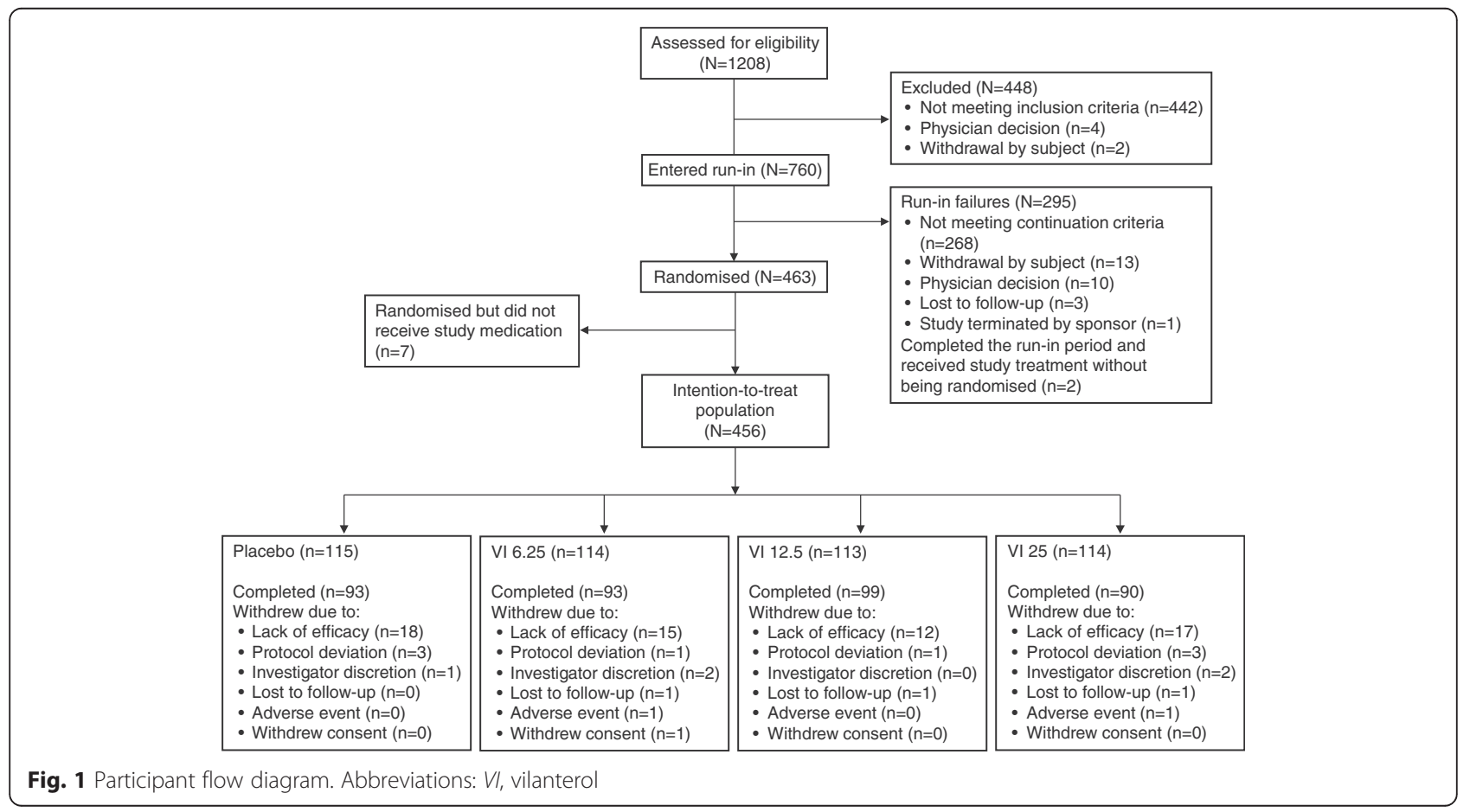


Table 1 Summary of demographic characteristics and baseline characteristics (ITT population)

\begin{tabular}{|c|c|c|c|c|c|}
\hline \multirow[t]{2}{*}{ Demographic } & Placebo & VI $6.25 \mu \mathrm{g}$ & $\mathrm{VI} 12.5 \mu \mathrm{g}$ & VI $25 \mu \mathrm{g}$ & Total \\
\hline & $N=115$ & $N=114$ & $N=113$ & $N=114$ & $N=456$ \\
\hline \multicolumn{6}{|l|}{ Sex, $n(\%)$} \\
\hline Female & $50(43)$ & $43(38)$ & $42(37)$ & $45(39)$ & $180(39)$ \\
\hline Male & $65(57)$ & $71(62)$ & $71(63)$ & $69(61)$ & $276(61)$ \\
\hline \multicolumn{6}{|l|}{ Age, years } \\
\hline Mean (SD) & $8.0(1.81)$ & $8.0(1.95)$ & $7.9(1.74)$ & $7.9(1.72)$ & $7.9(1.80)$ \\
\hline \multicolumn{6}{|l|}{ Age group, $n(\%)$} \\
\hline $5-7$ years & $51(44)$ & $48(42)$ & $42(37)$ & $46(40)$ & $187(41)$ \\
\hline $8-11$ years & $64(56)$ & $66(58)$ & $71(63)$ & $68(60)$ & $269(59)$ \\
\hline \multicolumn{6}{|l|}{ Race, $n(\%)$} \\
\hline White & $68(59)$ & $63(55)$ & $55(49)$ & $62(54)$ & $248(54)$ \\
\hline White and American Indian or Alaska Native & $20(17)$ & $19(17)$ & $26(23)$ & $24(21)$ & $89(20)$ \\
\hline American Indian or Alaska Native & $16(14)$ & $21(18)$ & $17(15)$ & $18(16)$ & $72(16)$ \\
\hline Asian & $6(5)$ & $6(5)$ & $7(6)$ & $6(5)$ & $25(5)$ \\
\hline African American/African heritage & $5(4)$ & $5(4)$ & $5(4)$ & $3(3)$ & $18(4)$ \\
\hline White and African American/African heritage & 0 & 0 & $2(2)$ & 0 & $2(<1)$ \\
\hline African American/African heritage and American Indian or Alaska Native & 0 & 0 & $1(<1)$ & 0 & $1(<1)$ \\
\hline African American/African heritage and Asian & 0 & 0 & 0 & $1(<1)$ & $1(<1)$ \\
\hline \multicolumn{6}{|l|}{ Ethnicity, $n$ (\%) } \\
\hline Hispanic/Latino & $81(70)$ & $82(72)$ & $82(73)$ & $82(72)$ & $327(72)$ \\
\hline Not Hispanic/Latino & $34(30)$ & $32(28)$ & $31(27)$ & $32(28)$ & $129(28)$ \\
\hline \multicolumn{6}{|l|}{ Baseline patient-reported outcomes } \\
\hline Rescue-free $24-h$ periods (SD), \% & $18.8(34.20)$ & $20.3(35.65)$ & $19.1(33.73)$ & $17.9(33.60)$ & - \\
\hline Symptom-free 24 -h periods (SD), $\%$ & $10.5(22.50)$ & $7.9(19.98)$ & $10.2(22.35)$ & $6.7(19.30)$ & - \\
\hline cACT score $\geq 20, n(\%)$ & $58(50)$ & $49(43)$ & $48(42)$ & $46(40)$ & - \\
\hline
\end{tabular}

CACT childhood asthma control test, ITT intention-to-treat, $S D$ standard deviation, $V I$ vilanterol

difference in rescue-free or symptom-free days was found for the VI 6.25 group.

Across all secondary PEF endpoints, small but nonsignificant increases were seen with VI treatments compared with placebo. However, as with the primary endpoint, no dose-response was observed (Table 3).

Children whose asthma was controlled at baseline (cACT score $\geq 20$ ) experienced only small improvements in cACT score following treatment with VI compared with placebo, whereas in children with a cACT score $<20$ at baseline, larger increases were observed (Table 3).

\section{Pharmacokinetics}

In total, 341 children (PK population) provided $780 \mathrm{PK}$ samples. There was a very high proportion of pre-dose samples with non-quantifiable levels of VI, especially in the two lower dose groups (91, 94 and $74 \%$ for the VI 6.25, VI 12.5 and VI 25 populations, respectively). At 10-15 min post-dose, the proportion of samples below the LLQ was 48,30 and $20 \%$ for the VI 6.25 , VI 12.5 and VI 25 groups, respectively. The concentration-time data for the current study were combined with data from previous studies conducted in children with asthma receiving either VI $25 \mu \mathrm{g}$ alone [18] or in combination with FF [17]. The mean plasma concentrations of VI 10 $-15 \mathrm{~min}$ post-dose were dose ordered and as expected for the doses administered $(17.27 \mathrm{pg} / \mathrm{mL}, 40.04 \mathrm{pg} / \mathrm{mL}$ and $90.47 \mathrm{pg} / \mathrm{mL}$, after treatment with VI $6.25 \mu \mathrm{g}$, VI $12.5 \mu \mathrm{g}$ and VI $25 \mu \mathrm{g}$, respectively).

\section{Safety}

The incidence of AEs during treatment was higher in the VI groups (28-33\%) than in the placebo group (22\%), but there was no apparent dose-ordering (Table 4). The incidence of AEs considered to be drug-related by the investigator was 3 and $2 \%$ in the VI 6.25 and VI 12.5 groups, respectively, with none reported in the placebo or VI 25 groups. The most frequently reported AE during the treatment period was nasopharyngitis. One child in each of the VI 6.25 and VI 25 groups experienced an AE leading to study withdrawal. The child in the VI 25 treatment group experienced an on-treatment non-fatal 
Table 2 Lung function measures at screening and baseline (ITT population)

\begin{tabular}{llllll}
\hline Lung function & Placebo & $\mathrm{Vl} 6.25 \mu \mathrm{g}$ & $\mathrm{VI} 12.5 \mu \mathrm{g}$ & $\mathrm{VI} 25 \mu \mathrm{g}$ & Total \\
measures & $\mathrm{N}=115$ & $\mathrm{~N}=114$ & $\mathrm{~N}=113$ & $\mathrm{~N}=114$ & $\mathrm{~N}=456$ \\
\hline
\end{tabular}

Screening

Pre-bronchodilator PEF (L/min)

$\begin{array}{llllll}n & 115 & 114 & 113 & 114 & 456 \\ \text { Mean } & 185.05 & 178.35 & 179.22 & 177.09 & 179.94 \\ \text { SD } & 59.30 & 55.67 & 60.57 & 55.68 & 57.74\end{array}$

Post-bronchodilator PEF (L/min)

$\begin{array}{llllll}n & 115 & 114 & 113 & 114 & 456 \\ \text { Mean } & 238.79 & 232.29 & 234.54 & 228.37 & 233.51 \\ \text { SD } & 67.41 & 69.80 & 69.79 & 72.29 & 69.71\end{array}$

Percentage of pre- to post-bronchodilator PEF (\%)

$\begin{array}{llllll}n & 115 & 114 & 113 & 114 & 456 \\ \text { Mean } & 76.95 & 76.86 & 75.87 & 78.02 & 76.93 \\ \text { SD } & 9.18 & 9.57 & 10.90 & 8.17 & 9.50\end{array}$

Pre-bronchodilator FEV $\mathrm{F}_{1}(\mathrm{~L})$

$\begin{array}{llllll}n & 91 & 91 & 97 & 102 & 381 \\ \text { Mean } & 1.405 & 1.370 & 1.374 & 1.361 & 1.377 \\ \text { SD } & 0.408 & 0.423 & 0.445 & 0.429 & 0.426\end{array}$

Post-bronchodilator FEV ${ }_{1}(\mathrm{~L})$

$\begin{array}{llllll}n & 99 & 98 & 96 & 103 & 396 \\ \text { Mean } & 1.700 & 1.702 & 1.699 & 1.680 & 1.695 \\ \text { SD } & 0.457 & 0.532 & 0.465 & 0.496 & 0.487\end{array}$

Pre-bronchodilator $\mathrm{FEV}_{1}(\% \text { predicted) })^{\mathrm{a}}$

$\begin{array}{llllll}n & 91 & 91 & 97 & 102 & 381 \\ \text { Mean } & 86.83 & 82.92 & 85.04 & 84.08 & 84.70 \\ \text { SD } & 19.83 & 17.00 & 17.34 & 16.77 & 17.73\end{array}$

Post-bronchodilator $\mathrm{FEV}_{1}(\% \text { predicted })^{\mathrm{a}}$

$\begin{array}{llllll}n & 99 & 98 & 96 & 103 & 396 \\ \text { Mean } & 106.81 & 101.10 & 104.34 & 104.58 & 104.22 \\ \text { SD } & 20.94 & 18.47 & 16.68 & 19.97 & 19.15\end{array}$

Baseline

Pre-bronchodilator PEF (L/min)

$\begin{array}{llllll}n & 115 & 114 & 113 & 114 & 456 \\ \text { Mean } & 186.27 & 185.08 & 181.24 & 179.39 & 183.00 \\ \text { SD } & 60.64 & 59.17 & 55.19 & 56.82 & 57.88\end{array}$

Percentage of pre- to post-bronchodilator PEF (\%)

\begin{tabular}{|c|c|c|c|c|c|}
\hline$n$ & 115 & 114 & 113 & 114 & 456 \\
\hline Mean & 77.77 & 79.54 & 77.58 & 79.13 & 78.51 \\
\hline SD & 10.49 & 9.09 & 10.11 & 9.77 & 9.88 \\
\hline \multicolumn{6}{|c|}{ Pre-bronchodilator $\mathrm{FEV}_{1}(\mathrm{~L})^{\mathrm{b}}$} \\
\hline$n$ & 96 & 91 & 97 & 103 & 387 \\
\hline Mean & 1.367 & 1.408 & 1.361 & 1.365 & 1.374 \\
\hline SD & 0.421 & 0.454 & 0.398 & 0.398 & 0.416 \\
\hline
\end{tabular}

Table 2 Lung function measures at screening and baseline (ITT population) (Continued)

\begin{tabular}{|c|c|c|c|c|c|}
\hline \multicolumn{6}{|c|}{ Pre-bronchodilator $\mathrm{FEV}_{1}$ (\% predicted) ${ }^{a, b}$} \\
\hline$n$ & 96 & 91 & 97 & 103 & 387 \\
\hline Mean & 84.37 & 83.99 & 85.43 & 85.75 & 84.91 \\
\hline SD & 19.35 & 16.99 & 17.66 & 18.38 & 18.08 \\
\hline
\end{tabular}

serious AE (SAE) of appendicitis and the child in the VI 6.25 treatment group experienced a viral respiratory tract infection. Neither AE was judged to be related to study treatment.

Nine (2\%) children experienced asthma exacerbations during the treatment period (one child in the placebo group, three in the VI 6.25 group, one in the VI 12.5 group and four in the VI 25 group). None of these children were hospitalised but eight were withdrawn from the study as a result.

The mean changes from baseline in vital signs at Week 4 were small and similar between the placebo and VI treatment groups (least squares mean change in systolic BP: 0.1-1.1 mm Hg; diastolic BP: $-0.1-0.4 \mathrm{~mm} \mathrm{Hg}$; pulse rate: $-0.7-0.4$ beats $/ \mathrm{min})$. Similarly, vital sign measurements at Week 2 and the maximum post-baseline changes showed only minor fluctuations from baseline. Abnormal ECG findings during the study were considered to be of potential clinical importance for $12(3 \%)$ children: two (2\%) children in the placebo group, six (5\%) children in the VI $6.25 \mu \mathrm{g}$ group and two (2\%) children in each of the VI 12.5 and VI 25 groups. No AEs relating to ECG findings were reported during the study, and no children were withdrawn due to meeting the protocol-defined ECG stopping criteria.

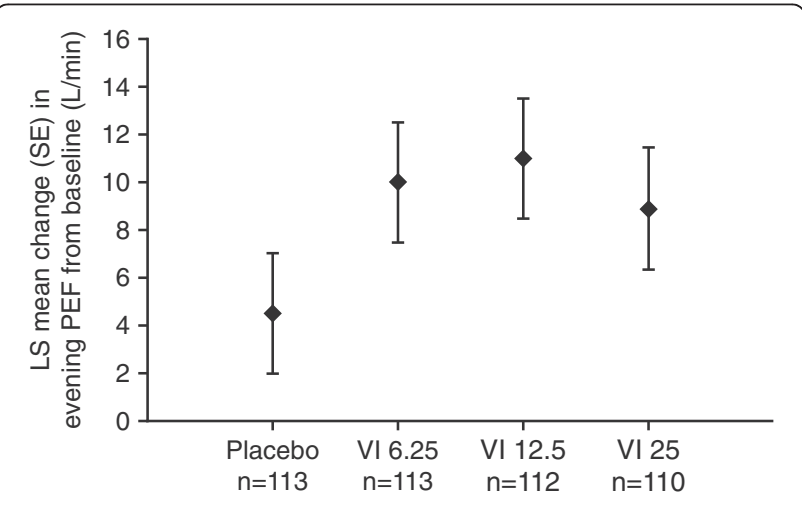

Fig. $2 \mathrm{LS}$ mean change from baseline in evening PEF averaged over Weeks 1 to 4 (ITT population). Abbreviations: ITT, intention-to-treat; $L S$, least squares; $P E F$, peak expiratory flow; $S E$, standard error, VI, vilanterol 
Table 3 Secondary outcomes (ITT population)

\begin{tabular}{|c|c|c|c|c|}
\hline & Placebo & VI $6.25 \mu \mathrm{g}$ & $\mathrm{VI} 12.5 \mu \mathrm{g}$ & $\mathrm{VI} 25 \mu \mathrm{g}$ \\
\hline & $N=115$ & $N=114$ & $N=113$ & $N=114$ \\
\hline \multicolumn{5}{|l|}{ Primary endpoint } \\
\hline \multicolumn{5}{|c|}{ Mean change from baseline in daily evening PEF Weeks 1-4 (L/min) } \\
\hline$n$ & 113 & 113 & 112 & 110 \\
\hline LS mean & 215.9 & 221.4 & 222.4 & 220.3 \\
\hline LS mean change (SE) & $4.5(2.53)$ & $10.0(2.53)$ & $11.0(2.54)$ & $8.9(2.56)$ \\
\hline Diff. vs placebo & & 5.5 & 6.4 & 4.4 \\
\hline $95 \% \mathrm{Cl}$ & & $-1.6,12.5$ & $-0.6,13.5$ & $-2.7,11.4$ \\
\hline$p$-value & & 0.127 & 0.073 & 0.227 \\
\hline \multicolumn{5}{|l|}{ Secondary endpoints } \\
\hline \multicolumn{5}{|c|}{ Change from baseline in trough $\mathrm{FEV}_{1}(\mathrm{~L})$ at Week 4 (LOCF) } \\
\hline$n$ & 85 & 83 & 86 & 86 \\
\hline LS mean & 1.616 & 1.559 & 1.632 & 1.586 \\
\hline LS mean change (SE) & $0.223(0.029)$ & $0.166(0.029)$ & $0.240(0.029)$ & $0.193(0.029)$ \\
\hline Diff. vs placebo & & -0.057 & 0.017 & -0.030 \\
\hline $95 \% \mathrm{Cl}$ & & $-0.138,0.024$ & $-0.063,0.096$ & $-0.110,0.051$ \\
\hline \multicolumn{5}{|c|}{ Change from baseline in percentage of rescue-free 24 -h periods, Weeks 1-4 } \\
\hline$n$ & 113 & 113 & 112 & 110 \\
\hline LS mean change (SE) & $14.4(2.97)$ & $12.2(2.97)$ & $15.8(2.98)$ & $23.1(3.01)$ \\
\hline Diff. vs placebo & & -2.3 & 1.3 & 8.7 \\
\hline $95 \% \mathrm{Cl}$ & & $-10.5,6.0$ & $-6.9,9.6$ & $0.4,17.0$ \\
\hline \multicolumn{5}{|c|}{ Change from baseline in percentage of symptom-free $24-h$ periods, Weeks 1-4 } \\
\hline$n$ & 113 & 113 & 112 & 110 \\
\hline LS mean change (SE) & $9.9(2.65)$ & $10.1(2.65)$ & $18.3(2.66)$ & $19.7(2.69)$ \\
\hline Diff. vs placebo & & 0.2 & 8.3 & 9.8 \\
\hline $95 \% \mathrm{Cl}$ & & $-7.2,7.5$ & $1.0,15.7$ & $2.3,17.2$ \\
\hline \multicolumn{5}{|c|}{ Change from baseline in morning PEF (L/min), Weeks 1-4 } \\
\hline$n$ & 114 & 113 & 112 & 110 \\
\hline LS mean & 206.3 & 211.8 & 213.8 & 213.5 \\
\hline LS mean change (SE) & $6.4(2.42)$ & $12.0(2.43)$ & $13.9(2.44)$ & $13.7(2.46)$ \\
\hline Diff. vs placebo & & 5.5 & 7.5 & 7.2 \\
\hline $95 \% \mathrm{Cl}$ & & $-1.2,12.3$ & $0.7,14.2$ & $0.4,14.0$ \\
\hline \multicolumn{5}{|c|}{ Change from Baseline in morning PEF (L/min), endpoint - Week 4 (LOCF) } \\
\hline$n$ & 114 & 113 & 112 & 110 \\
\hline LS mean & 207.2 & 213.1 & 216.9 & 214.2 \\
\hline LS mean change (SE) & $7.4(3.45)$ & $13.3(3.47)$ & $17.0(3.48)$ & $14.4(3.51)$ \\
\hline Diff. vs placebo & & 5.9 & 9.7 & 7.0 \\
\hline $95 \% \mathrm{Cl}$ & & $-3.7,15.6$ & $0.0,19.3$ & $-2.7,16.7$ \\
\hline \multicolumn{5}{|c|}{ Change from Baseline in evening PEF (L/min), endpoint - Week 4 (LOCF) } \\
\hline$n$ & 113 & 113 & 112 & 110 \\
\hline LS mean & 217.3 & 220.8 & 225.1 & 222.5 \\
\hline LS mean change (SE) & $5.9(3.44)$ & $9.4(3.44)$ & $13.7(3.45)$ & $11.1(3.48)$ \\
\hline Diff. vs placebo & & 3.5 & 7.8 & 5.2 \\
\hline $95 \% \mathrm{Cl}$ & & $-6.1,13.1$ & $-1.8,17.4$ & $-4.4,14.9$ \\
\hline
\end{tabular}


Table 3 Secondary outcomes (ITT population) (Continued)

\begin{tabular}{|c|c|c|c|c|}
\hline \multicolumn{5}{|l|}{ Other endpoints } \\
\hline \multicolumn{5}{|c|}{ Change from baseline in CACT score by baseline category at Week $4^{a}$} \\
\hline \multicolumn{5}{|c|}{ Baseline cACT Score <20 } \\
\hline$n$ & 48 & 57 & 59 & 56 \\
\hline LS mean & 19.5 & 19.8 & 20.2 & 20.9 \\
\hline LS mean change (SE) & $3.5(0.54)$ & $3.8(0.49)$ & $4.2(0.48)$ & $4.9(0.50)$ \\
\hline Diff. vs placebo & & 0.3 & 0.7 & 1.4 \\
\hline $95 \% \mathrm{Cl}$ & & $-1.2,1.7$ & $-0.7,2.1$ & $-0.1,2.9$ \\
\hline \multicolumn{5}{|c|}{ Baseline cACT Score $\geq 20$} \\
\hline$n$ & 50 & 39 & 47 & 36 \\
\hline LS mean & 22.9 & 21.5 & 21.9 & 22.5 \\
\hline LS mean change (SE) & $0.8(0.48)$ & $-0.5(0.53)$ & $-0.2(0.48)$ & $0.5(0.55)$ \\
\hline Diff. vs placebo & & -1.3 & -1.0 & -0.4 \\
\hline $95 \% \mathrm{Cl}$ & & $-2.8,0.1$ & $-2.4,0.4$ & $-1.8,1.1$ \\
\hline
\end{tabular}

CACT childhood asthma control test, $C l$ confidence interval, $F E V_{1}$ forced expiratory volume in one second, ITT intention-to-treat, $L S$ least squares, $P E F$ peak expiratory flow, SE standard error, VI vilanterol

${ }^{a}$ CACT data are post-hoc analyses

\section{Discussion}

In this study, we observed that once-daily inhaled VI added to a low dose of ICS in children with inadequately controlled asthma showed no statistically significant benefit in PEF measurements over placebo, which we believe also indicates a lack of clinical benefit for this outcome measure. The small numeric improvements over placebo in evening PEF following VI treatment were not statistically significant for the highest dose of $25 \mu \mathrm{g}$, and therefore no inferences were made for the lower doses investigated in this study. No apparent dose-response was observed. Therefore, the study was unable to demonstrate an incremental benefit in selected lung function measures with the addition of VI to open-label FP in this paediatric population.

We selected trough (evening) PEF as the primary endpoint because it was considered a more accessible measure of lung function than $\mathrm{FEV}_{1}$, as good quality spirometry may be difficult to perform in children [19]. However, PEF measurements have been reported to be variable $[20,21]$ and more so than $\mathrm{FEV}_{1}$ measurements [22]. Thus, PEF measurements may have introduced a level of under or over estimation of the treatment benefit. A previous study of the ICS/LABA combination $\mathrm{FP} /$ salmeterol in children ages 4-11 years, showed an increase in evening PEF compared with FP alone (mean change [standard

Table 4 Most frequent on-treatment AEs by preferred term (ITT population)

\begin{tabular}{|c|c|c|c|c|}
\hline \multirow[t]{2}{*}{$\mathrm{AE}$ (preferred term), $n(\%)$} & Placebo & VI $6.25 \mu \mathrm{g}$ & VI $12.5 \mu \mathrm{g}$ & VI $25 \mu \mathrm{g}$ \\
\hline & $N=115$ & $N=114$ & $N=113$ & $N=114$ \\
\hline Children with any $\mathrm{AE}$ & $25(22)$ & $33(29)$ & $37(33)$ & $32(28)$ \\
\hline Children with most frequent events & $15(13)$ & $27(24)$ & $26(23)$ & $18(16)$ \\
\hline Nasopharyngitis & $8(7)$ & $8(7)$ & $10(9)$ & $9(8)$ \\
\hline Headache & $4(3)$ & $6(5)$ & $2(2)$ & $2(2)$ \\
\hline Rhinitis & $3(3)$ & $2(2)$ & $3(3)$ & $1(<1)$ \\
\hline Respiratory tract infection viral & $1(<1)$ & $3(3)$ & $2(2)$ & $1(<1)$ \\
\hline Rhinitis allergic & 0 & $2(2)$ & $3(3)$ & $2(2)$ \\
\hline Abdominal pain & $1(<1)$ & 0 & $3(3)$ & $2(2)$ \\
\hline Bronchitis & $2(2)$ & $3(3)$ & $1(<1)$ & 0 \\
\hline Pharyngitis & $1(<1)$ & $3(3)$ & 0 & $2(2)$ \\
\hline Influenza & 0 & $4(4)$ & 0 & 0 \\
\hline Ear pain & 0 & 0 & $3(3)$ & 0 \\
\hline
\end{tabular}

All treatments were administered on a constant background of open-label FP $100 \mu \mathrm{g}$ twice daily. Table shows events that occurred in $\geq 3 \%$ in any treatment group $A E$ adverse event, ITT intention-to-treat, VI vilanterol 
error] from baseline over Weeks 1-12: $21.5 \mathrm{~L} / \mathrm{min}$ [2.43] and $15.1 \mathrm{~L} / \mathrm{min}$ [2.83], respectively) [23]. Furthermore, results of a Cochrane review comparing trials of 6-24 weeks duration in children found that a combination of LABA and ICS resulted in a significantly greater improvement in PEF compared with ICS monotherapy (morning PEF difference was $7.55 \mathrm{~L} / \mathrm{min}$ and evening PEF was $5.5 \mathrm{~L} / \mathrm{min}$ ) [6]. The treatment differences reported in these analyses are in line with our results, although statistical significance was not achieved in this study.

The children in the current study had inadequately controlled asthma and a mean percentage of pre- to post-bronchodilator PEF of $76.93 \%$. Therefore, a benefit would be expected in these children from the addition of LABA to their existing ICS therapy. Baseline cACT scores suggested a high proportion of controlled children (40-50\% cACT score $\geq 20$ ), which could provide a possible explanation for the lack of efficacy observed in this study. Another possible reason that no significant benefit in PEF was observed is that ICS provide good control of asthma in children, [24] thus reducing the potential for additional improvements in lung function. Of note, it is possible that children were more adherent to twice-daily ICS when in the trial compared with an unsupervised setting, as has been previously reported [25].

The mean pre- and post-bronchodilator $\mathrm{FEV}_{1}$ at screening was 84.7 and $104.2 \%$, respectively, suggesting that children recruited into this study had the potential for improvement in $\mathrm{FEV}_{1}$ measurements by use of a bronchodilator. Large increases from baseline in trough $\mathrm{FEV}_{1}$ at Week 4 (LOCF) were observed for both VI and placebo treatment groups, hence the small treatment differences versus placebo. Considering the small increases observed in morning and evening PEF, these increases in $\mathrm{FEV}_{1}$ may have been due to improved ability to perform spirometric measures over time, by both children and investigators, in addition to the benefits with ICS and improved adherence discussed above.

In the secondary efficacy endpoint analyses, an increase for rescue-free 24-h periods was observed in the VI 25 group compared with placebo. Additionally, notable increases in symptom-free 24-h periods were observed for both VI 12.5 and VI 25 groups. The increase in rescue-free 24-h periods observed in the VI 25 group and those in symptom-free $24-\mathrm{h}$ periods in the VI 12.5 and VI 25 groups exceed the lower bounds of the published minimal important differences in adults [26]. This finding indirectly supports the importance of including more than just lung function measurements in the main analyses of studies in children. Indeed, a large long-term study in children with asthma aged 5-12 years found that ICS treatment had no effect on lung function but resulted in improvements in airway responsiveness and health outcomes over the 4-6-year treatment period [27].

At the two lower doses of VI, the majority of PK samples were below quantifiable levels. The mean plasma concentration of VI 10-15 min post-dose was doseordered and systemic exposure observed for VI $25 \mu \mathrm{g}$ was similar to that observed in a Phase IIa study of FF/VI 100/25 $\mu \mathrm{g}$ in children [18]. As only one post-dose blood sample was collected, conclusions on maximum plasma concentration $\left(C_{\max }\right)$ and time to maximum plasma concentration $\left(t_{\max }\right)$ cannot be drawn from this study. However, studies in adults suggest that VI $25 \mu \mathrm{g}$ is rapidly absorbed and eliminated from the systemic circulation $[28,29]$ and in children VI $25 \mu \mathrm{g}$ has been shown to reach a $C_{\max }$ shortly after dosing $\left(t_{\max }\right.$ of $12 \mathrm{~min}$ ) [18].

The incidence of overall AEs was similar across the VI treatment groups and slightly higher than in the placebo group, although there was no dose-response. The most common on-treatment AEs were those commonly observed in paediatric populations with asthma. The single SAE reported was not considered to be related to study treatment and there were no asthma-related hospitalisations or fatalities reported. The low number of exacerbations in each treatment group prevents meaningful comparisons between treatments.

Potential limitations of this study were the difficulty in recruiting children with poorly-controlled asthma on a background of ICS, and the variability of PEF measurements which may have further masked any treatment differences. The difficulty in obtaining $\mathrm{FEV}_{1}$ in young children means that using this as a primary endpoint requires an intensive programme to support coaching good quality spirometry from all children at all visits. The high number of study assessments was also a barrier to recruitment, and we recommend that study assessments are kept to a minimum for studies in children with asthma. Moreover, additional inclusion criteria based on cACT score at baseline, reflecting inadequately controlled asthma, could be used to ensure recruitment of a more clinically relevant population.

\section{Conclusion}

In summary, we found that the three doses of VI investigated in this study $(6.25,12.5$ and $25 \mu \mathrm{g})$ did not significantly improve the change from baseline in daily pre-dose trough evening PEF in children ages 5-11 years and no dose-response was observed in change from baseline in evening PEF. Notable improvements over placebo were seen for VI 25 treatment in the percentage of rescuefree and symptom-free $24-\mathrm{h}$ periods. All treatments were well tolerated and no new safety concerns were identified during the study. 


\section{Abbreviations}

AE: adverse event; ANCOVA: analysis of covariance; BP: blood pressure; CACT: childhood asthma control test; $\mathrm{Cl}$ : confidence interval; $\mathrm{C}_{\text {max }}$ : maximum plasma concentration; ECG: electrocardiogram; $\mathrm{FEV}_{1}$ : forced expiratory volume in one second; FF: fluticasone furoate; FP: fluticasone propionate; ICS: inhaled corticosteroids; ITT: intention-to-treat; LABA: long-acting beta-2 agonist; LLQ: lower limit of quantification; LOCF: last observation carried forward; LS: least squares; MMRM: mixed modelling repeated measures; PEF: peak expiratory flow; PK: pharmacokinetic; PP: per protocol; SABA: shortacting inhaled beta-agonist; SAE: serious adverse event; SD: standard deviation; $S E$ : standard error; $t_{\max }$ : time to maximum plasma concentration; VI: vilanterol.

\section{Competing interests}

This study was funded by GSK (ClinicalTrials.gov identifier NCT01573767). The study sponsor was involved in the study design; the collection, analysis, and interpretation of data; the writing of the report; and the decision to submit the manuscript for publication. AJO, CHG and SAT are employees of GSK and hold stocks/shares in GSK. RAC received grant support from National Heart Lung Blood Institutes, GSK, Roche and AstraZeneca, and is a consultant for GSK. JG has received honoraria, travel and accommodation expenses to attend a GSK advisory board. SEP has received lecture fees from AstraZeneca and Boehringer Ingelheim, and consultancy fees from GSK, and Sandoz. CAS, $\mathrm{CV}$ and RMK have no competing interests to disclose.

\section{Authors' contributions}

AJO, CHG and SAT made substantial contributions to the conception and design of the study. RMK was involved in data acquisition. AJO, RAC, CHG, SEP, CAS, CV and JG were involved in data analysis and interpretation. All authors contributed to drafting the manuscript, revising it critically for important intellectual content and approved the final version to be published. All authors agree to be accountable for all aspects of the work in ensuring that questions related to the accuracy or integrity of any part of the work are appropriately investigated and resolved. All authors read and approved the final manuscript.

\section{Acknowledgements}

The authors wish to thank Ann Allen for pharmacokinetic expertise. Editorial support in the form of initial preparation of the outline based on input from all authors, and collation and incorporation of author feedback to develop subsequent drafts, assembling tables and figures, copyediting, and referencing was provided by Matthew Robinson, DPhil, of Fishawack Indicia Ltd, and was funded by GSK.

\section{Author details}

${ }^{1}$ GlaxoSmithKline, Stockley Park West, 1 - 3 Iron Bridge Road, Uxbridge, Middlesex UB11 1BT, UK. ' 2 epartment of Pediatrics, National Jewish Health, Denver, CO, USA. ${ }^{3}$ Southern California Clinical Trials, Newport Beach, CA, USA. ${ }^{4}$ University of Southern Denmark, Pediatric Research Unit, Kolding Hospital, Kolding, Denmark. ${ }^{5}$ University of Wisconsin School of Medicine and Public Health, Madison, WI, USA. ${ }^{6}$ Clinica Ricardo Palma, Javier Prado Este 1166 San Isidro, Lima, Perú. ${ }^{7}$ Blizard Institute, Queen Mary University London, London, UK.

\section{Received: 10 October 2015 Accepted: 30 March 2016} Published online: 05 April 2016

\section{References}

1. Nationwide Frequency and Costs of Potentially Preventable Hospitalizations, 2006: HCUP Statistical Brief \#72. 2009. http://www.hcup-us.ahrq.gov/reports/ statbriefs/sb72.jsp. Accessed September 2015.

2. British Thoracic Society. Scottish Intercollegiate Guidelines Network: British Guideline on the Mangement of Asthma: A national clinical guideline. Thorax. 2014;69:i1-i192.

3. Guidelines for the Diagnosis and Management of Asthma - Expert Panel Report 3. 2007. http://www.nhlbi.nih.gov/files/docs/guidelines/asthgdln.pdf. Accessed September 2015

4. Zhao Y, Han S, Shang J, Zhao X, Pu R, Shi L. Effectiveness of drug treatment strategies to prevent asthma exacerbations and increase symptom-free days in asthmatic children: a network metaanalysis. J Asthma. 2015;52(8):846-57.
5. Lemanske RF, Mauger DT, Sorkness CA, Jackson DJ, Boehmer SJ, Martinez FD, et al. Step-up therapy for children with uncontrolled asthma receiving inhaled corticosteroids. N Engl J Med. 2010;362:975-85.

6. Ni Chroinin M, Lasserson TJ, Greenstone I, Ducharme FM. Addition of longacting beta-agonists to inhaled corticosteroids for chronic asthma in children. The Cochrane Library 2009, Issue 3. Art. No.: CD007949. DOI: 10. 1002/14651858.CD007949.

7. de Groot EP, Kreggemeijer WJ, Brand PL. Getting the basics right resolves most cases of uncontrolled and problematic asthma. Acta Paediatr. 2015; 104(9):916-21.

8. Stanford RH, Gilsenan AW, Ziemiecki R, Zhou X, Lincourt WR, Ortega H. Predictors of uncontrolled asthma in adult and pediatric patients: analysis of the Asthma Control Characteristics and Prevalence Survey Studies (ACCESS). J Asthma. 2010;47:257-62.

9. Price D, Robertson A, Bullen K, Rand C, Horne R, Staudinger H. Improved adherence with once-daily versus twice-daily dosing of mometasone furoate administered via a dry powder inhaler: a randomized open-label study. BMC Pulm Med. 2010;10:1-9.

10. Toy EL, Beaulieu NU, McHale JM, Welland TR, Plauschinat CA, Swensen A, Duh MS. Treatment of COPD: relationships between daily dosing frequency, adherence, resource use, and costs. Respir Med. 2011;105:435-41.

11. SYMBICORT ${ }^{\oplus}$ budesonide and formoterol fumarate dihydrate: Highlights of prescribing information. 2010. http://www.accessdata.fda.gov/drugsatfda_ docs/label/2010/021929s021 lbl.pdf. Accessed September 2015.

12. ADVAIR. DISKUS fluticasone propionate and salmeterol: Highlights of prescribing information. 2014. http://www.accessdata.fda.gov/drugsatfda_ docs/label/2014/021077s053lbl.pdf. Accessed September 2015.

13. Bateman ED, O'Byrne P, Busse WW, Lotvall J, Bleecker ER, Andersen L, et al. Once-daily fluticasone furoate (FF)/vilanterol reduces risk of severe exacerbations in asthma versus FF alone. Thorax. 2014;69:312-9.

14. O'Byrne P, Bleecker ER, Bateman ED, Busse WW, Woodcock A, Forth R, et al. Once-daily fluticasone furoate alone or combined with vilanterol in persistent asthma. Eur Respir J. 2014;43:773-82.

15. Lin J, Kang J, Lee SH, Wang C, Zhou X, Crawford J, et al. Fluticasone furoate/vilanterol 200/25 mcg in Asian asthma patients: A randomized trial. Respir Med. 2015;109:44-53.

16. Slack RJ, Barrett VJ, Morrison VS, Sturton RG, Emmons AJ, Ford AJ, Knowles RG. In vitro pharmacological characterization of vilanterol, a novel longacting beta2-adrenoceptor agonist with 24-hour duration of action. J Pharmacol Exp Ther. 2013;344:218-30.

17. Oliver A, VanBuren S, Allen A, Hamilton M, Tombs L, Inamdar A, Kempsford R. Tolerability of fluticasone furoate/vilanterol combination therapy in children aged 5 to 11 years with persistent asthma. Clin Ther. 2014;36:928-39. e921.

18. Oliver A, VanBuren S, Allen A, Hamilton M, Tombs L, Kempsford R, Qaqundah $P$. Safety, tolerability, pharmacokinetics, and pharmacodynamics of vilanterol, a novel inhaled long-acting beta-agonist, in children aged 5-11 years with persistent asthma: a randomized trial. Clin Pharmacol Drug Dev. 2014;3:215-21.

19. Beydon N, Davis SD, Lombardi E, Allen JL, Arets HG, Aurora P, et al. An official American Thoracic Society/European Respiratory Society statement: pulmonary function testing in preschool children. Am J Respir Crit Care Med. 2007;175:1304-45.

20. Quanjer PH, Lebowitz MD, Gregg I, Miller MR, Pedersen OF. Peak expiratory flow: conclusions and recommendations of a working party of the European respiratory society. Eur Respir J Suppl. 1997;24:2S-8S.

21. Moeller A, Carlsen KH, Sly PD, Baraldi E, Piacentini G, Pavord I, et al. Monitoring asthma in childhood: lung function, bronchial responsiveness and inflammation. Eur Respir Rev. 2015;24:204-15.

22. Moore VC, Parsons NR, Jaakkola MS, Burge CB, Pantin CF, Robertson AS, Burge PS. Serial lung function variability using four portable logging meters. J Asthma. 2009:46:961-6.

23. Scott C, Wu W, Ellsworth A. Efficacy and safety of fluticasone propioante/ salmeterol DISKUS and fluticasone propionate DISKUS and HFA in children. Eur Respir J. 2005;26 Suppl 161:P1057.

24. Adams NP, Bestall JC, Lasserson TJ, Jones P, Cates CJ. Fluticasone versus placebo for chronic asthma in adults and children. Cochrane Database Syst Rev. 2008. Issue 4. Art. No.: CD003135. DOl: 10.1002/14651858.CD003135.pub4.

25. Bush A, Saglani S. Management of severe asthma in children. Lancet. 2010;376:814-25.

26. Clark M, Martin S, Svedsater H, Dale $P$, Jacques L. Measurement properties of an asthma symptom and rescue medication use diary. J Asthma. 2015;52:88-97. 
27. Long term effects of budesonide or nedocromil in children with asthma The childhood asthma management program research group. N Engl J Med. 2000;343:1054-63.

28. Hu C, Jia J, Dong K, Luo L, Wu K, Mehta R, et al. Pharmacokinetics and tolerability of inhaled umeclidinium and vilanterol alone and in combination in healthy Chinese subjects: a randomized, open-label, crossover trial. PLoS One. 2015;10:e0121264

29. Chen X, Zheng X, Jiang J, Hu P, Wu K, Zhuang L, et al. Pharmacodynamics and pharmacokinetics of fluticasone furoate/vilanterol in healthy Chinese subjects. Pharmacotherapy. 2015;35:586-99.

Submit your next manuscript to BioMed Central and we will help you at every step:

- We accept pre-submission inquiries

- Our selector tool helps you to find the most relevant journal

- We provide round the clock customer support

- Convenient online submission

- Thorough peer review

- Inclusion in PubMed and all major indexing services

- Maximum visibility for your research

Submit your manuscript at www.biomedcentral.com/submit
Biomed Central 